\title{
DEVELOPMENT OF A POTENTIAL MODEL TO SUPPORT THE ASSESSMENT AND INTRODUCTION OF INDUSTRY 4.0 TECHNOLOGIES
}

\author{
D. Schneider $\otimes$, T. Huth, T. Vietor, P. Schumacher, C. Weckenborg and T. Spengler \\ Technische Universität Braunschweig, Germany \\ $\triangle$ da.schneider@tu-braunschweig.de
}

\begin{abstract}
As digitalisation progresses, the demands placed on companies are increasing at all stages of the product generation process. In order to address these requirements and maintain economic strength, companies must implement innovative and intelligent technologies. Small and mediumsized enterprises in particular are confronted with various obstacles, the overcoming of which is addressed by the "Potential Model" presented in this publication.
\end{abstract}

Keywords: design methodology, evaluation, technology development

\section{Introduction}

Since its first appearance, the term "Industry 4.0" has been part of global discussions. (Wichmann et al., 2019) Keeping pace in the fourth industrial revolution ever since is highly important for nations with a high proportion of production in added value, such as e.g. Germany, Japan or Italy. (Kagermann et al., 2016) Thereby the understanding of the term "production" goes beyond the pure manufacturing and assembly of products and covers the entire product generation. (Abele and Reinhart, 2011) Industry 4.0 (I4.0) technologies offer a variety of improvement potentials in the areas of productivity, resource conservation or product design and "Industry 4.0" is therefore still a hot discussed and important topic from an entrepreneurial point of view. (Kagermann et al., 2016) In the course of digitalization, the industry inter alia is confronted with an increasing product complexity as well as an increasing demand for customer-specific products. Due to networking and global competition, product lifecycles are also becoming shorter and new products and technologies have to be developed and produced in ever shorter time frames. (Rudtsch, 2016; Rauch et al., 2016; Abele and Reinhart, 2011) From an entrepreneurial point of view, I4.0 technologies must therefore promote the dynamics of product creation, as well as its connectivity, autonomy and adaptability. (Wichmann et al., 2019; Reik et al., 2006) Despite the importance and potentials of the implementation of I4.0 technologies, a hesitating behaviour of SMEs in particular can be identified. (Wichmann et al., 2019)

\subsection{Obstacles to the implementation of $\mathbf{1 4 . 0}$}

The implementation of I4.0 technologies requires the willingness of companies for changes in product generation processes. Especially SMEs are confronted with a big challenge compared to large corporations. (Kagermann et al., 2016) Requirements for I4.0 and deficits of SMEs usually interact 
with each other at this point. For example, the I4.0-implementation is usually associated with high initial investments, which poses an even greater risk for SMEs due to their lower liquidity. (Faller and Feldmüller, 2015; Koch et al., 2014) Another prerequisite is the ability to look ahead and beyond one's own product and production structures to new technologies and approaches. According to this requirement SMEs in particular are at a disadvantage compared with large corporations due to their lower manpower and, as a result, less possibilities for action. (Faller and Feldmüller, 2015) The fact that companies need to invest early in innovative technologies to gain a strong economic foothold interacts with the risk of focusing on the wrong technology. This risk is particularly high for SMEs due to the reduced resources available to assess the impacts of a technology. Compared to large corporations, there is a lack of both manpower and experience. (Koch et al., 2014) From the extensive literature research according to Wichmann et al. (2019), further challenges emerge, such as the fundamental question "How?" the introduction of I4.0 can look like in detail, as well as the initially increasing system and process complexity, which requires a high planning and resource expenditure.

\subsection{Current research efforts and results}

In order to address the obstacles described in the previous section, a great research effort is being made under the topic "Industry 4.0". (Pereira and Romero, 2017; Wichmann et al., 2019) Therefore, a large number of approaches, procedures and methods exists for the implementation of I4.0. A major part of these research efforts and results focuses on the production phase of the product generation process. (Terstegen et al., 2019) Due to the multitude of solution approaches, only a selection of these will be referred to below in order to illustrate the major research priorities. During the research project "Intro 4.0", enabling and implementation strategies for I4.0 were developed. In addition to the development of methods to increase employee productivity, this included a procedure for risk and potential assessment of I4.0 technologies. Focus of the research work was the production, whereby cross-production effects of I4.0 technologies, for example regarding to product development, were not recorded. (Lanza et al., 2016) The study "Gemini 4.0" addresses the methodical support of the development of new business concepts based on I4.0 technologies. The fourth industrial revolution is considered and evaluated as a whole, which is why the effects of individual I4.0 technologies and their advantages and disadvantages are not the focus of the research work. (Gausemeier et al., 2017) The "Guideline I4.0" focuses on supporting SMEs and provides guidance regarding to the implementation of I4.0 technologies through a five-stage process. The I4.0 toolbox used during this process refers not only to production but also to the product. With the help of the guideline, potentials for the use of I4.0 technologies can be identified. However, no specific technology is recommended for implementation, let alone predicting its effects. (VDMA - Forum Industrie 4.0, 2019) Support for SMEs in developing a roadmap for the implementation of I4.0 is offered by the Acatech study "Industry 4.0 Maturity Index". In addition to production, functional areas such as product development, logistics, service, marketing and sales are also considered. By classifying individual aspects using a questionnaire, entrepreneurs can determine the maturity level of their company and are enabled to identify hotspots that offer potential for the use of I4.0 technologies. However, similar to the "Guideline Industry 4.0", also no reference is made to specific technologies, but optimization proposals are conveyed at a process level. (Schuh et al., 2017)

\subsection{Objective and focus of research}

"Industry 4.0" is still up to date and in progress. As described in Section 1.2, there exists a number of obstacles to the fourth industrial revolution and their overcoming poses a major challenge for SMEs in particular. There is a variety of methods and tools available to help overcome these obstacles, but most of them are characterised by a production-heavy perspective, or lead to general roadmaps that do not relate to specific technologies neither their evaluation. For this reason the "Potential Model" is presented in this publication. Its application is intended to support SMEs in selecting and forecasting the impact of I4.0 technologies. The following questions and obstacles should be addressed by the Potential Model:

- What does the current state of the SME looks like?

- Where is potential for I4.0 to be used and to improve the SME's current situation?

- Which specific I4.0 technology addresses the hotspots of the SME?

- At a rough qualitative level: What can the impact of the I4.0 technology on the SME look like? 
The Potential Model is not to support the technical implementation of a I4.0 technology, neither to generate a quantitative or specific process based forecast of the effects of a potential I4.0 implementation. Its main objective is to give SMEs an initial orientation which I4.0 technologies exists and are potentially fitting to their current state, measured on their individual assessment. To introduce the Potential Model its basics components and their relations among each other will be explained in Section 2, followed by a description regarding to the development and design of the PM. In Section 3 an exemplary application of the PM will be executed to illustrate its basic functionality and benefit. As usual, the publication concludes with a short summary and an outlook on further research.

\section{Basic components and design of the potential model}

The Potential Model (PM) can be subdivided into several components, which were developed on the basis of different theories and which interact with each other in different ways. Before presenting the PM as a whole, this section first describes the basic components and their interrelationships.

\subsection{Evaluation criteria and the motivation to implement $\mathbf{I 4 . 0}$}

From the comparative study from the Institute of Applied Industrial Engineering and Ergonomics (IFAA) of process models for the introduction and implementation of digitalization measures it can be emerged that the recording of the actual state of a company, as well as its motivation, represents a basis for the implementation support of I4.0. (Terstegen et al., 2019) For this reason, Lembeck et al. (2019) make use of a tool in the form of various "criteria" in the course of the development of an evaluation methodology for the integration of I4.0 technologies into product development. The criteria are used to describe the business objectives on which a possible I4.0 implementation is based. (Lembeck et al., 2019; Kaplan and Norton, 1996) This approach was adopted for the PM, whereby the criteria serve only secondarily to record the company objectives and primarily to determine the actual state. The aim is to look at the company from different perspectives beyond production and to identify possible deficits and options for action. In total, the PM includes 18 criteria that are based on extensive literature research and the work in the "Synus" research association of the TU Braunschweig. Thus, the evaluation criteria determined during the development of the evaluation methodology by Lembeck et al. (2019) could be used as a basis. In a next step this collection of criteria was revised, filtered and expanded within the framework of the Synus Innovation Network on the basis of the experience values of various experts from the network. The procedure for literature research, which was necessary to complete the catalogue of criteria, was based on the procedure of Lembeck et al. (2019), whereby the criteria did not have to be explicitly related to product development. As the main purpose of the PM is to support SMEs with the selection of suitable I4.0 technologies to improve their current situation, only criteria are included that have interdependencies with technologies of the "Synus I4.0 technology catalogue" (see Section 2.4). Thus every criteria and its rating can as well be used to display the current state of the company as to help offering suitable I4.0 technology solutions. Moreover, every criteria is connected to a key performance indicator (KPI) so that every criteria is objectively measureable to avoid subjectivity regarding the criteria. After the completion of the catalogue the evaluation criteria had to be systematically categorized. Basis for the classification were the "Balanced Score Card Perspectives", which will be described in Section 2.3.

\subsection{Criteria rating scale}

The rating scale, which enables the individualized evaluation of individual criteria by various representatives of a company, was developed on the basis of the "Likert Scale". (Thielsch et al., 2012) According to Thielsch's theory, the rating scale of the PM has an optimum spectrum of 1 to 5, whereby a rating of 1 corresponds to an insufficiently fulfilled criterion by the company and 5 corresponds to a criterion already very well fulfilled by or within the company.

\subsection{Holistic company view}

In the area of enterprise controlling, in which a holistic and process-oriented view of the enterprise is fundamentally important, various methods exist for this purpose. (Lembeck et al., 2019) The "Balanced Score 
Card" (BSC) is one of these methods and is classified by Erdmann as a suitable observation and valuation approach in a comparison of various performance measurement concepts. (Erdmann, 2013) Lu et al. (2018) and Lee and Seo (2016) also confirm the suitability of the BSC method for a holistic view of a company. For the systematic categorisation of the evaluation criteria in the course of the development of the PM, the perspectives of the BSC were used as a basis. Figure 1 shows the BSC perspectives taken up in the PM.

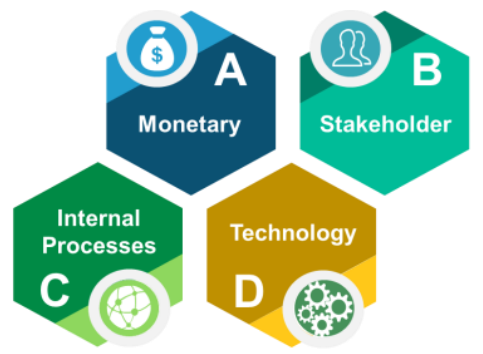

Figure 1. BSC-perspectives used in the PM

The use of these perspectives ensures that the PM and its evaluation criteria cover all I4.0 relevant company aspects and phases of the product development process. Furthermore, it enables an efficient and systematic classification of the evaluation criteria themselves.

\subsection{Synus 14.0 technology catalogue}

By using the evaluation criteria presented in Section 2.1 and structuring them according to the BSC perspectives (Section 2.2), the actual state of a SME can be analysed in a wide spectrum of perspectives. According to this state, a higher-level recommendation (rough qualitative) about which I4.0 technology is potentially suitable for an improvement can be given (See Section 1.3). This feature addresses the I4.0 technology implementation challenge of SMEs in form of disorientation which I4.0 technology even exists or is potentially fitting to the SMEs state and values. In order to ensure a higher-level technology recommendation, the evaluation criteria of the PM are connected to specific I4.0 technologies, which are listed in an I4.0 technology catalogue. Based on an extensive literature and industry research this catalogue was developed and validated during the research efforts of the innovation network Synus. The catalogue includes several information for each identified I4.0 technology such as a functional description, elementary technical components, fields of action as well as initial and subsequent expenditure for the implementation. Furthermore each evaluation criteria listed in the PM is included in the technology catalogue and potential effects are specifically assessed for each I4.0 technology. The assessment is based on expert knowledge and know-how of members and researchers of the innovation network Synus.

Table 1 shows exemplary and analogously a part of the structure of the I4.0 technology catalogue where the potential effects of I4.0 on the evaluation criteria of the PM are rough qualitative established. According to the criteria rating scale (see Section 2.2) the effects of the technologies can be positive, neutral or negative. The long-term goal is to validate and readjust these expert knowledge based assessments over time as well as with recurring use of the PM and feedback of the SMEs (KPI, see Section 2.1).

Table 1. Analogous substructure of the $\mathbf{1 4 . 0}$ technology catalogue

\begin{tabular}{|c|c|c|c|c|c|c|c|c|}
\hline \multirow{3}{*}{$\begin{array}{c}\text { I4.0 } \\
\text { technology }\end{array}$} & \multicolumn{8}{|c|}{ BSC-Perspective and Evaluation Criteria } \\
\hline & \multicolumn{4}{|c|}{ Stakeholder perspective } & \multicolumn{3}{|c|}{ Technical perspective } & $\ldots$ \\
\hline & $\begin{array}{l}\text { Customer } \\
\text { integration }\end{array}$ & $\begin{array}{c}\text { Customer } \\
\text { statisfaction }\end{array}$ & $\begin{array}{c}\text { Supplier } \\
\text { integration }\end{array}$ & $\begin{array}{c}\text { Ergnonomic } \\
\text { workplace } \\
\text { design }\end{array}$ & $\begin{array}{l}\text { Tracability } \\
\text { of products }\end{array}$ & $\begin{array}{l}\text { Traceability } \\
\text { of processes }\end{array}$ & $\begin{array}{c}\text { Cyber- } \\
\text { Securit } \\
y\end{array}$ & \\
\hline $\begin{array}{c}\text { Virtual start- } \\
\text { up }\end{array}$ & +2 & +1 & 0 & 0 & 0 & 0 & 0 & \\
\hline $\begin{array}{c}\text { AR- } \\
\text { supported } \\
\text { assembly }\end{array}$ & 0 & 0 & 0 & +3 & +3 & +2 & 0 & \\
\hline$\ldots$ & & & & & & & & \\
\hline
\end{tabular}




\subsection{Design principles}

In the preceding sections, the essential components and interrelationships of the PM were described, which enable the orientation assistance in the form of the actual state analysis and I4.0 recommendation. In a next step, the question of the design structure of the PM must be clarified. There are many different possibilities for the visual and logical structuring of the model components. It can be stated that the evaluation criteria as well as the BSC perspectives contain information and thus provide knowledge at different levels. According to Nowack (1997) and De Jong (1996), this knowledge can be classified and structured with regard to different perspectives and purposes. Table 2 lists the four types of knowledge according to Nowack (1997). Due to the scope of the publication a reference is made to Nowack (1997), De Jong (1996) for more detailed information.

Table 2. Types of knowledge (Nowack, 1997)

\begin{tabular}{|l|l|l|}
\hline Knowledge Type & Use / Application / Characteristics & Example \\
\hline Strategic & Least domain specific & Planning \\
\hline Problem-situational & $\begin{array}{l}\text { Use to find relevant problem } \\
\text { interpretation }\end{array}$ & Recalling similar problem \\
\hline Procedural & Action focused, domain specific & Design Method \\
\hline Declarative & Needs interpretation to apply & Facts, The Design \\
\hline
\end{tabular}

Thus, "strategic knowledge" forms the basis of modelling, which is further subdivided and detailed by "problem-oriented knowledge". The procedural and declarative knowledge then delivers specific hints and marginal information in the next model level. As already mentioned, the components of the PM can be assigned to the different types of knowledge and thus visually structured. An example for a design approach using the knowledge types and their interactions is the "Digital Compass" by McKinsey, which was developed to identify potential applications of I4.0 technologies.

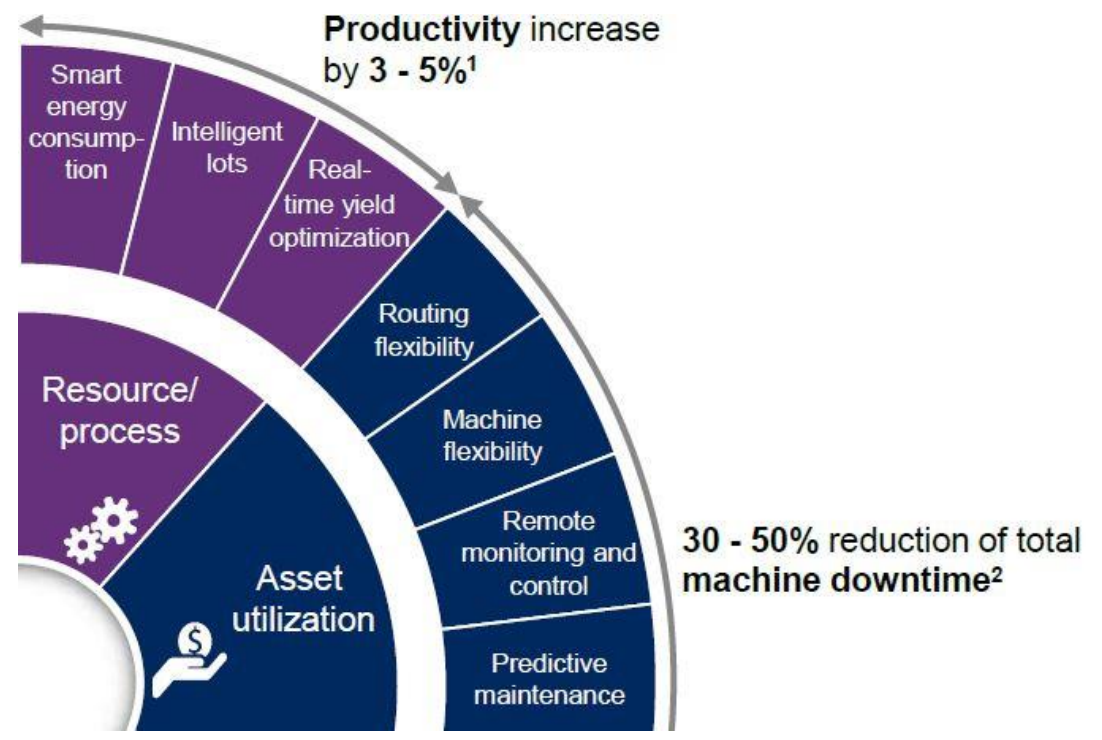

Figure 2. Partial section of McKinseys digital compass (McKinsey, 2016)

McKinsey's Digital Compass presents eight essential value drivers such as Resource/Process or Quality as a basis and assigns different I4.0 technologies such as "Predictive maintenance" or "Smart energy consumption" to them. (McKinsey, 2016) The value drivers are to be assigned to strategic knowledge, which is not very domain-specific and thus forms a suitable basis for the assignment and classification of I4.0 technologies. The I4.0 technologies themselves can be assigned to problem-oriented knowledge because they provide the measures for realizing the company's potential. The design of the Digital Compass can thus be regarded as an effective way of visualizing the relations between the strategic and problem-oriented knowledge level. The declarative knowledge could be stored in the form of technical marginal information on the I4.0 technologies. (Şahin et al., 2018) With regard to the PM-Design the BSC 
perspectives can be assigned to strategic knowledge and form the basic level. The following model level is represented by the problem-oriented knowledge, to which the evaluation criteria can be assigned, since these enable the actual state of a SME to be recorded. Further information of specific I4.0 technologies can be assigned to the declarative and procedural knowledge and is provided to the PM by a database. The knowledge levels of the PM and their relations are shown in Figure 3 for clarification.

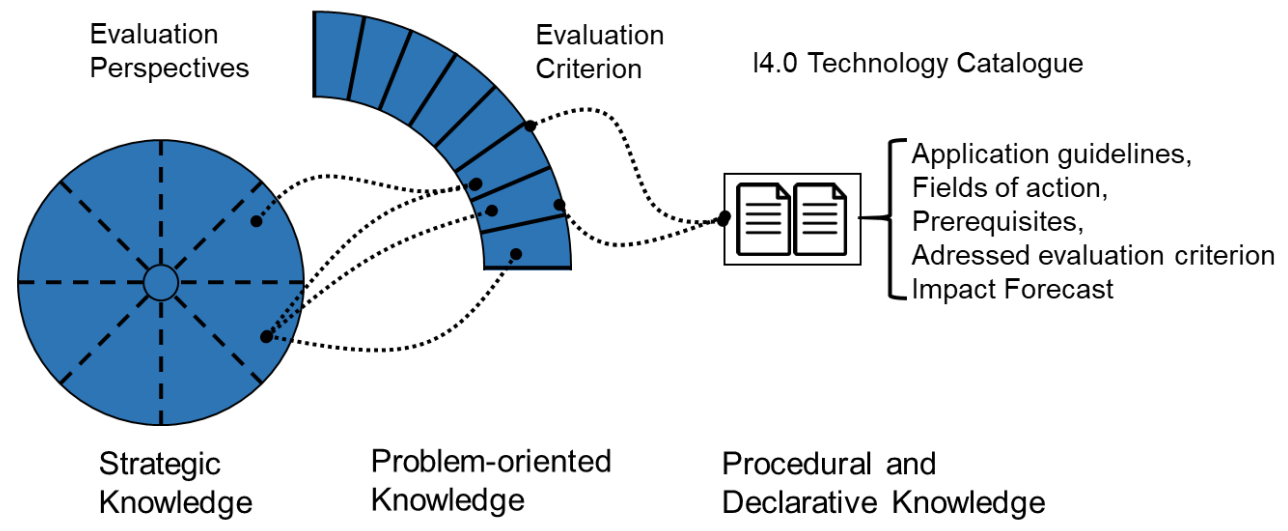

Figure 3. Design elements of the PM

The assignment of the components of the PM to the knowledge types according to Nowack (1997) and the visualization approach of these knowledge types with the help of the wheel model according to McKinsey (2016) form the basis for the design and structure of the PM, as presented in the following.

\subsection{Potential model}

Based on the elements described in the previous sections, as well as their relations and design possibilities, the PM shown in Figure 4 was developed, which addresses the research questions of I4.0 described in Section 1.

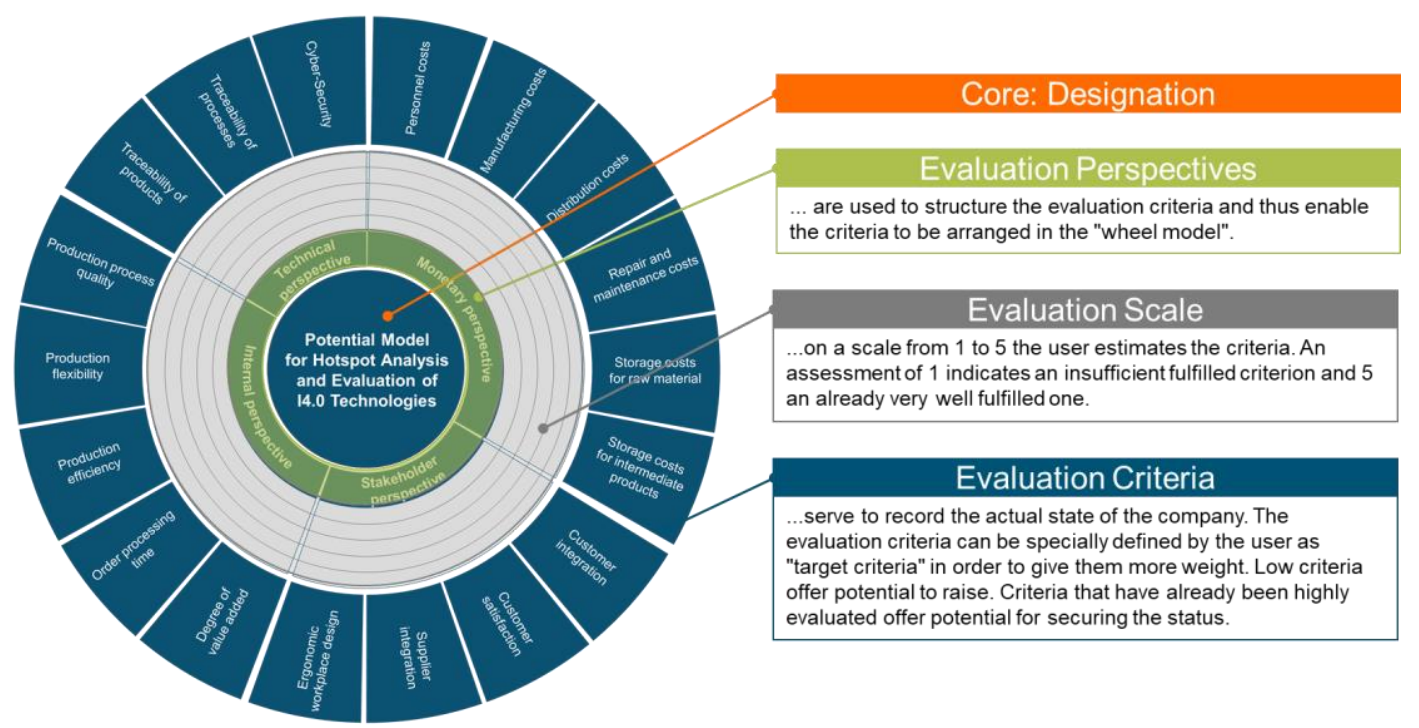

Figure 4. The potential model and its elements

The inner and fundamentally structuring circle of the PM is formed by the evaluation perspectives, followed by an evaluation level at which the evaluation criteria are evaluated manually. The evaluation criteria themselves form the outer ring of the PM, which is based on McKinsey's Digital Compass in the form of a wheel model. The evaluation criteria serve the actual recording of the actual state of the company as well as the hotspot analysis. In the following section, the functionality of the individual components and the PM as a whole are illustrated using an example. 


\section{Application of the potential model}

The PM is suitable for both workshop and digital use. In both cases, the company's representatives estimate the actual status of the individual evaluation criteria and enter their assessment in the evaluation area. The fulfilment assessment of a criterion in the company at the current point in time can vary significantly depending on the expertise of the representatives. Different representatives with varying perspectives enable a broader view on the current situation of the company. In a next step, the individual evaluations are averaged and interpolated. The resulting curve shows striking mountains and valleys. The valleys of the evaluation curve reveal criteria which, in the opinion of the representatives, are insufficiently or only insufficiently covered or fulfilled by the company. At this point, the users of the PM can now decide whether the defective criteria should be classified as "critical" and thus as "target criteria". An evaluation criterion that receives the status of a target criterion is to be improved by the introduction of I4.0 technologies and receives special attention in the selection and recommendation of suitable technologies. Figure 5 shows the valleys of the evaluation curve and the target criteria. Both the actual state of the company as well as its hotspots and change targets were recorded.

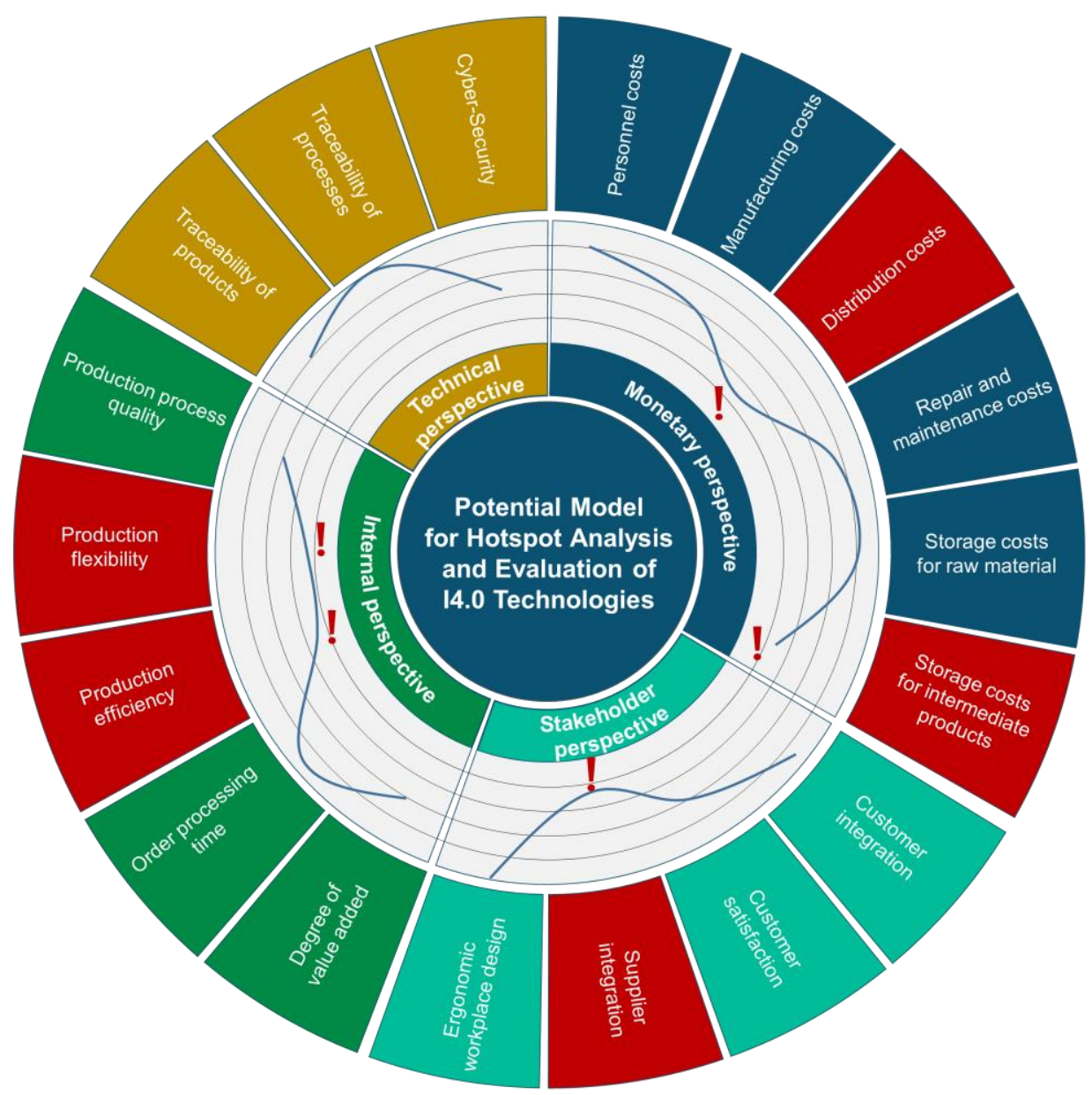

Figure 5. Evaluation curve and target criteria of the potential model

The next step is the recommendation of one or more I4.0 technologies with potential for improvement. As described in Section 2.4, this is realized with the I4.0 technology catalogue where the effects of each I4.0 technology is assessed for every criteria of the PM. In this way target criteria (PM) and positive affected criteria (catalogue) point out I4.0 technology with the potential to improve the SMEs current state. The expected effects or improvements of an I4.0 technology according to the experts' assessment can then be visualized in the PM. This is shown in Figure 6. 


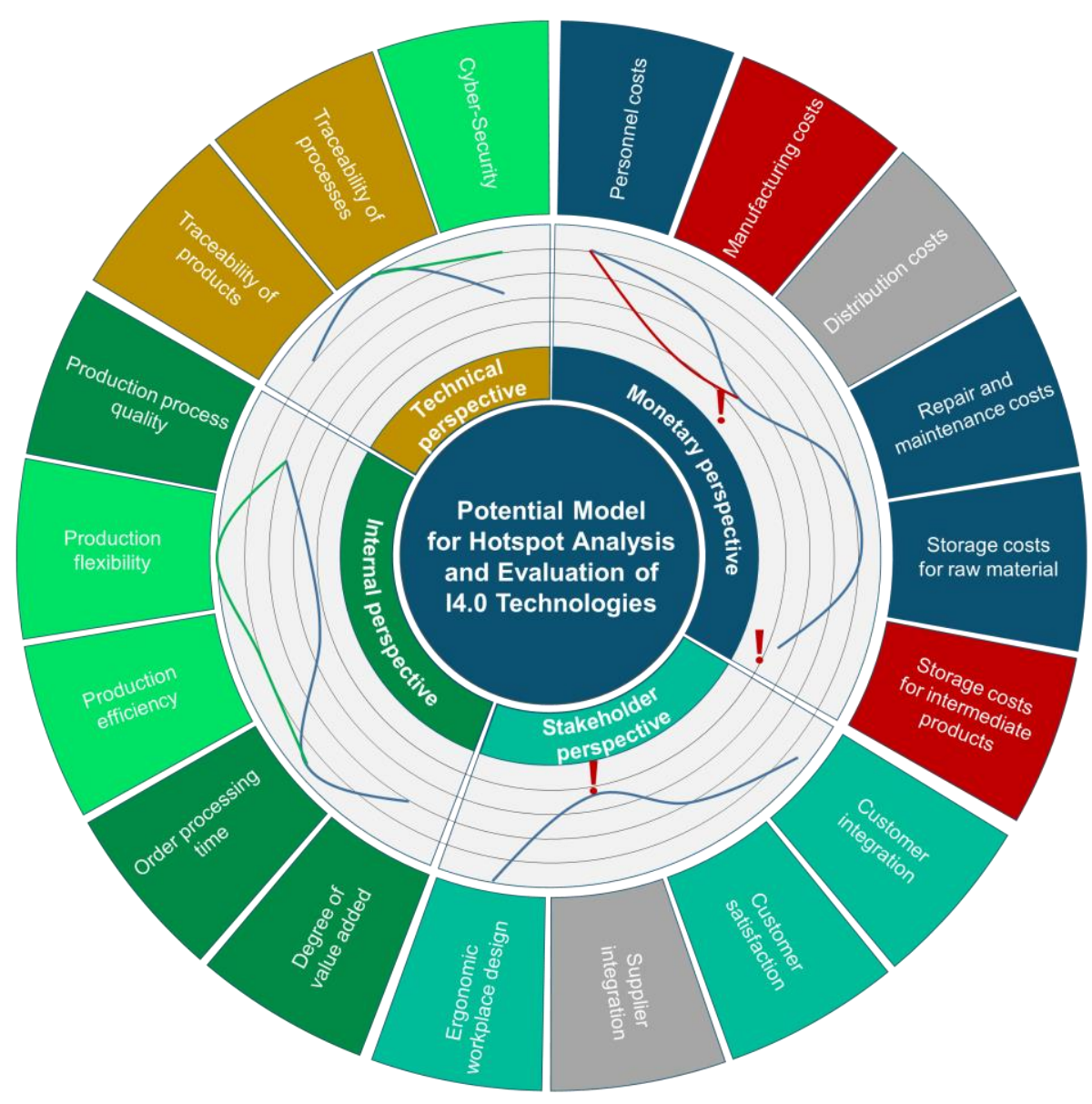

Figure 6. Potential model: Impact forecast of a specific 14.0 technology

The impact prognosis of an I4.0 technology shown in Figure 6 shows that the technology has a particularly positive effect in terms of improving the target criteria. It is also evident that the technology cannot address all improvement potentials of the company. Some evaluation criteria as well as one target criterion remain unaffected by the I4.0 effects according to the experts' prognosis. In favour of the improvement of some target criteria, it can also happen that an evaluation criterion deteriorates.

The final step in applying the PM is to use the impact forecast to decide whether new deficits in evaluation criteria are acceptable in favour of improvements in the target criteria and which implementation of the recommended I4.0 technologies should be further investigated and pursued. No further support will be provided by the PM, than creating a first orientation in the confusing dimension of I4.0 and providing a first, rough estimation of possible effects of an I4.0 technology. The PM provides the basis for further, more expensive investigations and simulations for the introduction of specific I4.0 technologies and reduces the risk of misplaced investigations significantly.

\section{Summary and further research}

"Industry 4.0 " is still an important topic, which is ever since its first appearance still hot discussed. There exists a wide-ranged understanding of "Industry 4.0 " and its technologies, but in one thing there is unity: I4.0 technologies offer a wide variety of improvement potentials in different areas such as productivity, cross-disciplinary cooperation or e.g. product design.

Despite all these improvement potentials a restrained behaviour can be observed especially at SMEs.

As a reason for that, a variety of obstacles such as high investment efforts in conjunction with high risks, caused by insufficient assessability of technology implementation impacts, can be identified.

In order to support the overcoming of these obstacles a huge research effort is being made and a large number of methods and tools to implement I4.0 technologies is being developed. However 
most of these approaches focus on one specific phase of the product generation process such as production or provide a general overview to implement I4.0 technologies without evaluating specific technologies and their impacts. In purpose to close this research gap, a model to identify I4.0 technology implementation potentials regarding to the actual state of a company is introduced in this publication. First the basic elements and their relations to each other are described, followed by the explanation of the development and visualization process of the model. Ensuing the so called "Potential Model" is introduced as a whole. Before this publication concludes with a short summary and an outlook on further research, the functionality of the Potential Model is demonstrated by means of an exemplary application.

With regard to further research the evaluation criteria of the Potential Model will be further validated by workshops, surveys and applications of the Potential Model in the industry. Furthermore, the completeness of the I4.0 technology catalogue will further be reviewed, as well as the included declarative and procedural knowledge and the roughly qualitative effect assessment of the technologies on the evaluation criteria of the Potential Model.

\section{Acknowledgements}

This paper was developed in the research project "Synus" (Methods and tools for the synergetic conception and evaluation of Industry 4.0 technologies) which is funded by the European Regional Development Fund (EFRE | ZW 6- 85012454) and managed by the project management agency NBank.

\section{References}

Abele, E. and Reinhart, G. (2011), Zukunft der Produktion: Herausforderungen, Forschungsfelder, Chancen, Carl Hanser Fachbuchverlag, s.l.

Erdmann, M.-K. (2013), Supply chain performance measurement: Operative und strategische Management- und Controllingansätze, 3rd ed., EUL Verlag, Köln.

Faller, C. and Feldmüller, D. (2015), "Industry 4.0 Learning Factory for regional SMEs", Procedia CIRP, Vol. 32, pp. 88-91.

Gausemeier, J. et al. (2017), Mit Industrie 4.0 zum Unternehmenserfolg - Integrative Planung von Geschäfts modellen und Wertschöpfungssystemen, Heinz Nixdorf Institut, Paderborn.

Jong, T.D. and Ferguson-Hessler, M.G.M. (1996), "Types and qualities of knowledge”, Educational Psychologist, Vol. 31 No. 2, pp. 105-113.

Kagermann, H. et al. (2016), Industrie 4.0 in a Global Context: Strategies for Cooperating with International Partners (acatech STUDY), Herbert Utz Verlag, Munich.

Kaplan, R.S. and Norton, D.P. (1996), "Linking the Balanced Scorecard to Strategy", California Management Review, Vol. 39 No. 1, pp. 53-79.

Koch, V. et al. (2014), Industrie 4.0 - Chancen und Herausforderungen der vierten industriellen Revolution, Fachverlag Moderne Wirtschaft, Frankfurt.

Lanza, G. et al. (2016), "Befähigungs- und Einführungsstrategien für Industrie 4.0", ZWF Zeitschrift für wirtschaftlichen Fabrikbetrieb, Vol. 111 No. 1-2, pp. 76-79.

Lee, S. and Seo, K.-K. (2016), “A Hybrid Multi-Criteria Decision-Making Model for a Cloud Service Selection Problem Using BSC, Fuzzy Delphi Method and Fuzzy AHP”, Wireless Personal Communications, Vol. 86 No. 1, pp. 57-75.

Lembeck, H. et al. (2019), Evaluation methodology for the process integration of industry 4.0 solutions into Design, Fraunhofer IAO, Stuttgart.

Lu, M.-T. et al. (2018), "A hybrid MCDM and sustainability-balanced scorecard model to establish sustainable performance evaluation for international airports", Journal of Air Transport Management, Vol. 71, pp. 9-19.

McKinsey. (2016). "Industry 4.0 at McKinsey's model factories", available at: http://sf-eu.net/wp-content/uploads/ 2016/08/mckinsey-2016-industry-4.0-at-mckinseys-model-factories-en.pdf (accessed 14 November 2019).

Nowack, M.L. (1997), Design guideline support for manufacturability, Selwyn College, Cambride.

Pereira, A.C. and Romero, F. (2017), "A review of the meanings and the implications of the Industry 4.0 concept", Procedia Manufacturing, Vol. 13, pp. 1206-1214.

Rauch, E., Dallasega, P. and Matt, D.T. (2016), "The Way from Lean Product Development (LPD) to Smart Product Development (SPD)", Procedia CIRP, Vol. 50, pp. 26-31.

Reik, M.P. et al. (2006), "Design for Changeover (DFC)", In: Blecker, T. and Friedrich, G. (Eds.), Mass Customization: Challenges and Solutions, International Series in Operations Research \& Management Science, Vol. 87, Kluwer Academic Publishers, Boston, pp. 111-136. 
Rudtsch, V. (2016), Methodik zur Bewertung von Produktionssystemen in der frühen Entwicklungsphase, Dissertation, Dissertation, Universität Paderborn, Paderborn.

Şahin, T. et al. (2018), "How to Foster Innovation? Findings and Hypotheses for Collaborations between Research and Industry", Proceedings of the DESIGN 2018 15th International Design Conference, May, 2124, 2018, Faculty of Mechanical Engineering and Naval Architecture, University of Zagreb, Croatia; The Design Society, Glasgow, UK, pp. 1945-1956.

Schuh, G. et al. (2017), Industrie 4.0 Maturity Index. Managing the Digital Transformation of Companies (acatech STUDY), Herbert Utz Verlag, Munich.

Terstegen, S. et al. (2019), "Vergleichsstudie über Vorgehensmodelle zur Einführung und Umsetzung von Digitalisierungs- maßnahmen in der produzierenden Industrie", In: GfA (Ed.), Frühjahrskongress der Gesellschaft für Arbeitswissenschaften - Arbeit interdisziplinär analysieren - bewerten - gestalten, Vol. 65, Dortmund.

Thielsch, M.T., Lenzner, T. and Melles, T. (2012), "Wie gestalte ich gute Items und Interviewfragen?”, In: Praxis der Wirtschaftspsychologie: Themen und Fallbeispiele für Studium und Anwendung, Vol. 2, Monsenstein u. Vannerdat, Münster, pp. 221-240.

VDMA - Forum Industrie 4.0 (2019), Guideline Industrie 4.0 - Guiding principles for the implementation ofIndustrie 4.0 in small and medium sized businesses, VDMA Verlag GmbH, Frankfurt.

Wichmann, R.L., Eisenbart, B. and Gericke, K. (2019), "The Direction of Industry: A Literature Review on Industry 4.0", Proceedings of the Design Society: International Conference on Engineering Design, Vol. 1 No. 1, pp. 2129-2138. 